\title{
Adsorption of hexavalent chromium ions from aqueous solution by graphene nanosheets: kinetic and thermodynamic studies
}

\author{
E. K. Goharshadi • M. B. Moghaddam
}

Received: 11 October 2014/Revised: 9 December 2014/ Accepted: 30 December 2014/Published online: 27 January 2015

(C) Islamic Azad University (IAU) 2015

\begin{abstract}
In the present study, a batch system was used to investigate the adsorption of chromium (VI) ions from an aqueous solution by graphene nanosheets. Graphene is decorated with functional groups containing oxygen such as epoxy and hydroxyl on the basal plane. The large negative charge density available on graphene causes effective adsorption of chromium (VI) ions from aqueous solutions. The adsorption capacity and rate of chromium (VI) ions at different temperatures, adsorbent dosages, initial concentrations, and contact times were evaluated. The kinetic study illustrated that the adsorption of chromium (VI) ions onto graphene obeys the pseudo-second-order model with activation energy of $21.91 \mathrm{~kJ} \mathrm{~mol}^{-1}$. The chromium (VI) ions adsorption was well explained using Dubinin-Radushkevich isotherm model. The values of standard enthalpy, entropy, and Gibbs free energy changes at $25^{\circ} \mathrm{C}$ were calculated as $686.07 \mathrm{~kJ} \mathrm{~mol}^{-1}, 2.38 \mathrm{~kJ} \mathrm{~mol}^{-1} \mathrm{~K}^{-1}$, and $-22.43 \mathrm{~kJ} \mathrm{~mol}^{-1}$, respectively. In this work, graphene was prepared via a green method. Transmission electron microscopy, Fourier transform-infrared spectroscopy, energy-dispersive X-ray analysis, powder X-ray diffraction, Boehm's titration, and $\mathrm{N}_{2}$ adsorption-desorption techniques revealed a high-quality few-layer nanosheets of graphene with surface area and inter-planar spacing of $594.7 \mathrm{~m}^{2} \mathrm{~g}^{-1}$ and $3.6 \AA$, respectively.
\end{abstract}

E. K. Goharshadi $(\bowtie) \cdot$ M. B. Moghaddam

Department of Chemistry, Faculty of Sciences, Ferdowsi

University of Mashhad, 91775-1436 Mashhad, Iran

e-mail: gohari@ferdowsi.um.ac.ir

E. K. Goharshadi

Center of Nano Research, Ferdowsi University of Mashhad,

91775-1436 Mashhad, Iran
Keywords Chromium (VI) removal · Graphene · Dubinin-Radushkevich isotherm - Thermodynamics

\section{Introduction}

Rapid development of industries such as metal-plating facilities, mining operations, fertilizer industries, tanneries, batteries, paper industries, and pesticides has led to an increased discharged wastewater containing heavy metal ions $(\mathrm{Cr}, \mathrm{Cd}, \mathrm{Hg}, \mathrm{Pb}$, and $\mathrm{As}$ ) into the environment ( $\mathrm{Fu}$ and Wang 2011). In addition, most heavy metal ions are nondegradable into non-toxic products; hence, their concentrations must be reduced to acceptable levels before discharging them into environment. Otherwise, these could pose threats to and/or affect public health (Badmus et al. 2007). Therefore, effective recovery of heavy metal ions is as important as their removal from waste streams.

One of the heavy metal ions that has been a major focus in water and wastewater treatments is hexavalent $\mathrm{Cr}$ (VI) ion (Karthikeyan et al. 2005). Chromium, a group 6 transition metal, is the 21 st most abundant elements in the earth's crust with an average concentration of $100 \mathrm{ppm}$ (Emsley 2011). Its concentration ranges are $0.001-3 \mathrm{mg} \mathrm{g}^{-1}$ in soil, $5 \times 10^{-6}-0.8 \times 10^{-3} \mathrm{mg} \mathrm{mL}^{-1}$ in seawater, $2.6 \times 10^{-5}$ $-5.2 \times 10^{-3} \mathrm{mg} \mathrm{mL}^{-1}$ in rivers and lakes (Kotaś and Stasicka 2000), and $5 \times 10^{-4}-270 \mathrm{mg} \mathrm{mL}^{-1}$ in industrial wastewater (Patterson 1985). Chromium ion has been considered as one of the top 16 toxic pollutants. Because of its carcinogenic and teratogenic characteristics on the public health, it has become a serious concern (Gardea-Torresdey et al. 2000). Water pollution by chromium ions is due to both natural sources and various industrial processes (Özdemir et al. 2011). Cr (VI) enters water bodies from industries such as electroplating, leather tanning, cement, iron, steel, paint, 
ink, dyes, aluminum, and textile and inorganic chemicals production (Gao et al. 2008). In the environment, chromium ions usually exist as $\mathrm{Cr}$ (III) or $\mathrm{Cr}$ (VI) species. $\mathrm{Cr}$ (VI) species may be in the form of dichromate $\left(\mathrm{Cr}_{2} \mathrm{O}_{7}{ }^{2-}\right)$, hydrochromate $\left(\mathrm{HCrO}_{4}{ }^{-}\right)$, or chromate $\left(\mathrm{CrO}_{4}{ }^{2-}\right)$ in a solution of different pH values (Park and Jang 2002). Due to the repulsive electrostatic interactions, the $\mathrm{Cr}$ (VI) anion species are generally poorly adsorbed by the negatively charged soil particles in the environment, and hence, they can transfer freely in the aqueous environments ( $\mathrm{Li}$ et al. 2009). The $\mathrm{Cr}$ (III) species in aqueous solutions, however, may take the form of $\mathrm{Cr}^{3+}, \mathrm{CrOH}^{2+}$, or $\mathrm{Cr}(\mathrm{OH})_{2}^{+}$depending on the solution $\mathrm{pH}$ values. As these species normally carry positive electric charges, they are relatively easy to be adsorbed on the negatively charged soil particles and thus are less mobile than the $\mathrm{Cr}(\mathrm{VI})$ species in the environment (Deng and Bai 2004). Cr (VI) species are known to be more toxic than Cr (III) species (Ponder et al. 2000).

According to the National Toxicology Program (NTP), the International Agency for Research on Cancer (IARC), $\mathrm{Cr}$ (VI) is a human carcinogen (Cancer and Humans 2001; Gupta and Babu 2006) that modifies the DNA transcription process causing important chromosomic aberration (PérezCandela et al. 1995). The permissible limit of chromium for drinking water is $0.1 \mathrm{mg} \mathrm{L}^{-1}$ (as total chromium) in EPA standard. In addition, National Iranian standard for $\mathrm{Cr}$ (VI) concentration in drinking water is $0.05 \mathrm{mg} \mathrm{L}^{-1}$ (Nameni et al. 2008).

Various technologies have been employed for removing $\mathrm{Cr}$ (VI) ion from water (Ghosh 2009; Hota et al. 2008; Wang and Chen 2009). The most commonly applied physicochemical treatment methods are: (1) precipitation as hydroxides, carbonates, or sulfides and subsequent liquidsolids separation by gravity settling, and flotation or filtration, (2) sorption (adsorption, ion exchange), (3) membrane processes, (4) electrolytic recovery and, (5) liquid-liquid extraction (Wang and Chen 2009). Although all these techniques can be employed to remove heavy metal ions, they have inherent advantages and limitations in applications and are often limited by technical and economic issues (Fu and Wang 2011; Wang and Chen 2009).

Among above treatment techniques, adsorption has been one of the most widely used methods to remove chromium species from aqueous solutions (Deng and Bai 2004; Stafiej and Pyrzynska 2007). Adsorption is a surface phenomenon and defined as the increase in the concentration of a particular component at the surface or interface between two phases (Gupta et al. 2012a). Various adsorbents have been used for removal of $\mathrm{Cr}$ (VI) ions like silica gel, polymers, carbon nanotubes, activated carbon, bentonite, fly ash, clays, zeolites, chitosan, peat moss, biosorbents, and food wastes. (Chakir et al. 2002; Saleh and Gupta 2012). However, some of these adsorbents have low adsorption capacities or need long adsorption equilibrium times, while others may have difficulty for regeneration and reuse even though they have high adsorption capacity and fast adsorption equilibrium (Nakano et al. 2001). The low adsorption capacity of $\mathrm{Cr}$ (VI) ions on the traditional adsorbents like activated carbon and high cost have restricted their wide applications (Dias et al. 2007). On the other hand, graphene has been used as an efficient adsorbent to remove heavy metal ions from water or wastewater (Zhu et al. 2011) because of its relatively low-cost, theoretically high surface area $\left(\sim 2,630 \mathrm{~m}^{2} \mathrm{~g}^{-1}\right)$, and high mesoporous volumes (Upadhyay et al. 2014).

The present study was performed to evaluate graphene as an adsorbent for the removal of $\mathrm{Cr}$ (VI) ions from aqueous solutions by systematic evaluation of parameters such as $\mathrm{Cr}$ (VI) ion concentration, time, adsorbent dosage, and temperature. The Freundlich, Langmuir, and DubininRadushkevich adsorption isotherms were applied to study the adsorption. The thermodynamic parameters such as standard Gibbs free energy change $\left(\Delta G^{\circ}\right)$, standard enthalpy change $\left(\Delta H^{\circ}\right)$, and standard entropy change $\left(\Delta S^{\circ}\right)$ were also calculated.

\section{Materials and methods}

\section{Materials}

$\mathrm{Mg}$ ribbons, dry ice, hydrochloric acid (37\%), and $\mathrm{NaOH}$ $\left(99.998 \%\right.$ ) bought from Merck, $\mathrm{NaHCO}_{3}$ (Riedel, $99.5 \%$ ), and $\mathrm{Na}_{2} \mathrm{CO}_{3}$ (Fluka) are the materials used in preparation of graphene. Potassium dichromate $\left(\mathrm{K}_{2} \mathrm{Cr}_{2} \mathrm{O}_{7}, 99 \%\right)$ and 1,5diphenyl carbazide (DPC) were purchased from Alfa Aesar Company. $O$-phosphoric acid $\left(\mathrm{H}_{3} \mathrm{PO}_{4}, 85 \mathrm{wt} \%\right)$ was purchased from Fisher Scientific. Deionized water was used for preparation of all solutions. All materials were used as received and were of analytical grade.

Preparation of graphene

Graphene was synthesized similar to our previous work (Moghaddam et al. 2013). Briefly, $2 \mathrm{~g} \mathrm{Mg}$ ribbons was burned in dry ice at room temperature. The black products were washed with $2 \mathrm{M} \mathrm{HCl}$ at room temperature several times to remove the $\mathrm{MgO}$ formed and any remaining $\mathrm{Mg}$ metal. The reaction mixture was then centrifuged and washed with deionized water until the $\mathrm{pH}$ of filtrate became neutral. The dark products were dried overnight at $90{ }^{\circ} \mathrm{C}$ in the vacuum oven. The yield was $450 \mathrm{mg}(90 \%)$.

The amounts of oxygen functional groups on the surface of graphene were determined by Boehm's titration method (Goertzen et al. 2010). For this purpose, $0.2 \mathrm{~g}$ of adsorbent was added into $50 \mathrm{~mL}$ of the solutions of $\mathrm{NaHCO}_{3}(0.1 \mathrm{~N})$, 
$\mathrm{Na}_{2} \mathrm{CO}_{3}(0.1 \mathrm{~N})$, and $\mathrm{NaOH}(0.1 \mathrm{~N})$. The conical flasks were sealed and shaken at room temperature for $48 \mathrm{~h}$. After elapsing this time, the suspensions were centrifuged, and $20 \mathrm{~mL}$ filtrates and $15 \mathrm{~mL}$ of $0.1 \mathrm{M}$ hydrochloric acid were added to neutralize the unreached bases. The solutions were then back-titrated with $0.1 \mathrm{M}$ sodium hydroxide. The acidity was calculated by measuring the volume of $\mathrm{HCl}$ consumed due to the titration with the solutions of $\mathrm{NaOH}$, $\mathrm{Na}_{2} \mathrm{CO}_{3}$, and $\mathrm{NaHCO}_{3}$. The amounts of oxygen functional groups on the surface of graphene including carboxylic, lactonic, and phenolic groups were 18.435, 3.775, and $0.540 \mathrm{meq}^{-1}$, respectively.

\section{Sorption experiments}

Stock and other solutions of $\mathrm{Cr}$ (VI) ions were prepared by dissolving $\mathrm{K}_{2} \mathrm{Cr}_{2} \mathrm{O}_{7}$ in deionized water. The potassium dichromate solution containing $1,000 \mu \mathrm{g} \mathrm{L}^{-1}$ chromium was treated with graphene. Briefly, the chromium solution was mixed with predetermined amount of graphene $(0.02$, $0.1,0.2,0.3$, and $0.6 \mathrm{~g} \mathrm{~L}^{-1}$ ). The solution was stirred at room temperature for $5 \mathrm{~min}$. Then, graphene was separated from the solution with a centrifuge (Fisher Scientific, Centrific 228). The clear solution was then collected and subjected to colorimetric analysis to determine the final chromium concentration.

For the kinetic study, the graphene concentration was maintained at $0.6 \mathrm{~g} \mathrm{~L}^{-1}$ in the neutral solution for different adsorption times. For colorimetric analysis (Zhu et al. 2011), the aforementioned clear solution $(5.25 \mathrm{~mL})$ was transferred to a test tube containing $O$-phosphoric acid $(0.50 \mathrm{~mL}$, $4.5 \mathrm{M})$ and DPC $\left(0.25 \mathrm{~mL}, 5 \mathrm{~g} \mathrm{~L}^{-1}\right)$. After keeping at room temperature for $30 \mathrm{~min}$ for color development, the absorbance of the samples was measured using UV-vis spectrophotometer (CARY1) at $540 \mathrm{~nm}$. The equilibrium adsorption capacity $\left(q_{\mathrm{e}}, \mathrm{mg} \mathrm{g}^{-1}\right)$ and the removal efficiency were calculated using following equations:

$q_{\mathrm{e}}=\frac{\left(C_{\mathrm{o}}-C_{\mathrm{e}}\right) \cdot V}{W}$

Removal $(\%)=\frac{C_{\mathrm{o}}-C_{\mathrm{e}}}{C_{\mathrm{o}}} \times 100$

where $C_{\mathrm{o}}$ and $C_{\mathrm{e}}\left(\mathrm{mg} \mathrm{L}^{-1}\right)$ are the initial and equilibrium concentrations of $\mathrm{Cr}(\mathrm{VI})$ ions in aqueous solution and $V$ is the volume of the solution (L). $W$ stands for the mass of adsorbent (g).

\section{Characterization}

A FTIR (Shimadzu 4300) spectrum of graphene was recorded to examine graphene nanosheets (Fig. 1). The bands at 3421,1565 , and $1196 \mathrm{~cm}^{-1}$ are attributed to $\mathrm{O}-\mathrm{H}$ stretching vibrations of adsorbed water molecules and

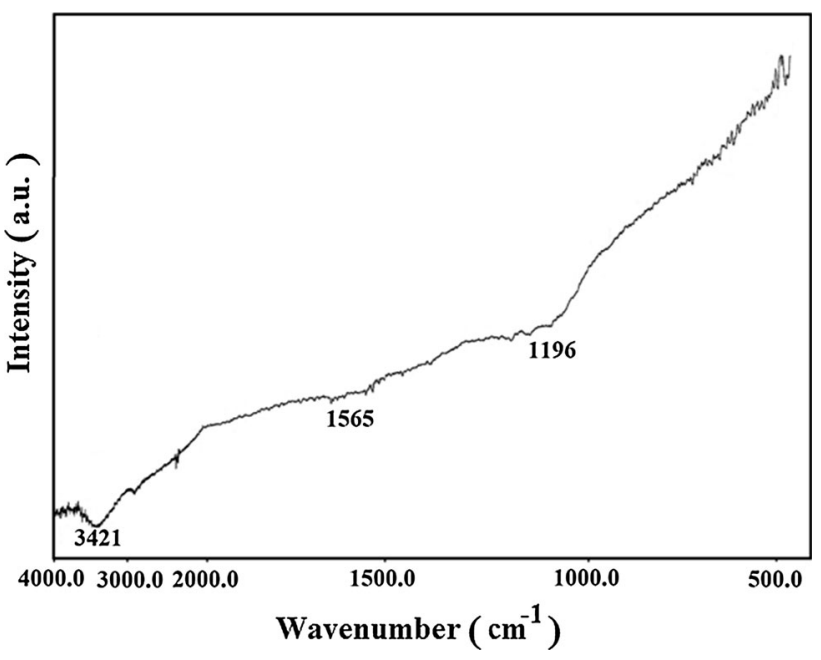

Fig. 1 FT-IR spectrum of few-layer graphene. Copied with permission from Moghaddam et al. (2013). Copyright 2014 Elsevier B. V.

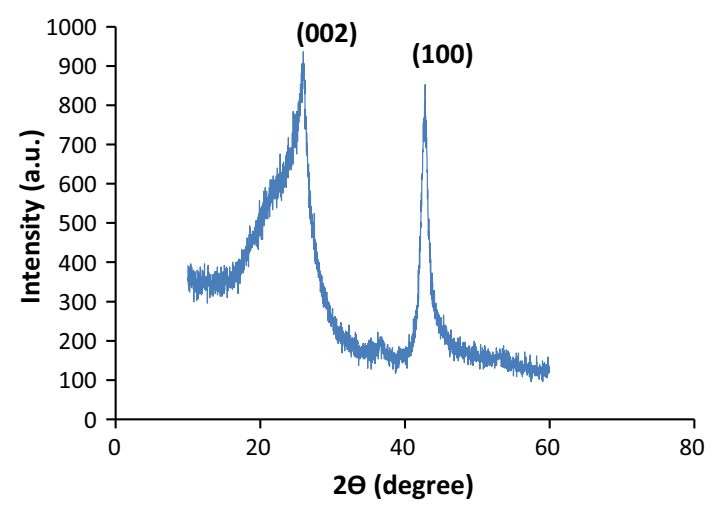

Fig. 2 XRD pattern of the graphene nanosheets. Copied with permission from Moghaddam et al. (2013). Copyright 2014 Elsevier B. V.

structural $\mathrm{OH}$ groups (Lian et al. 2010), the skeletal vibration of graphene nanosheets (Guo et al. 2009), and C-C band (Guo et al. 2010), respectively.

The powder XRD (Philips PW1800) pattern of graphene is shown in Fig. 2. Graphene shows two characteristic peaks at around $2 \theta=26.3^{\circ}$ and $43.2^{\circ}$. The first broadness peak corresponds to the (002) inter-planar spacing of $3.42 \AA$ (Chakrabarti et al. 2011; Su et al. 2011; Wang et al. 2008). The second sharp and intensive peak at about $43.2^{\circ}$ is corresponding to the (100) plane which may overlap with one of the $\mathrm{MgO}$ peaks (Chakrabarti et al. 2011).

Figure 3a shows TEM (LEO $912 \mathrm{AB}$ ) image of the fewlayer graphene. As this figure shows, the few-layer graphene resembles transparent and rippled silk waves. The elemental analysis obtained from EDX (LEO 1450 VP) (Fig. 3b) are C 85 (atm wt\%), Mg 15.79 (atm wt\%), and O 14.11 (atm wt\%). The amounts of $\mathrm{Mg}$ and $\mathrm{O}$ are mainly due to the trapped $\mathrm{MgO}$ and some absorbed $\mathrm{O}$. The BET surface area of the prepared graphene was measured as $594.7 \mathrm{~m}^{2} \mathrm{~g}^{-1}$. 


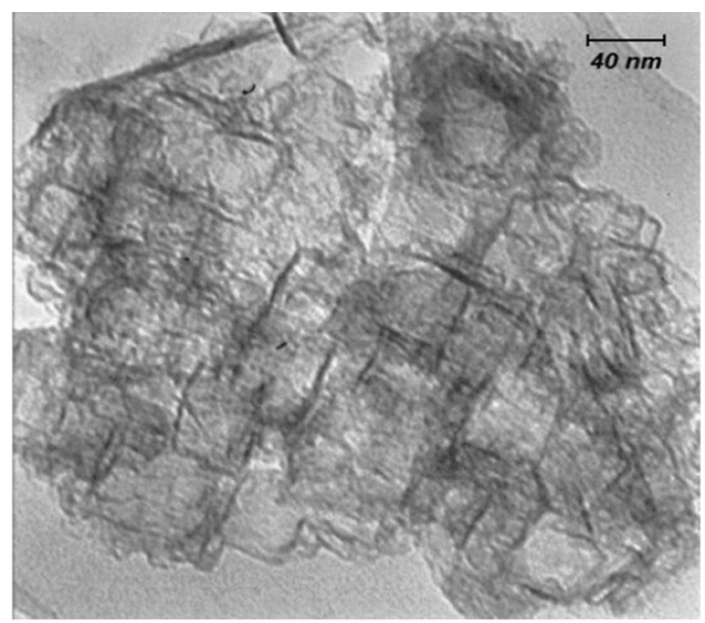

a

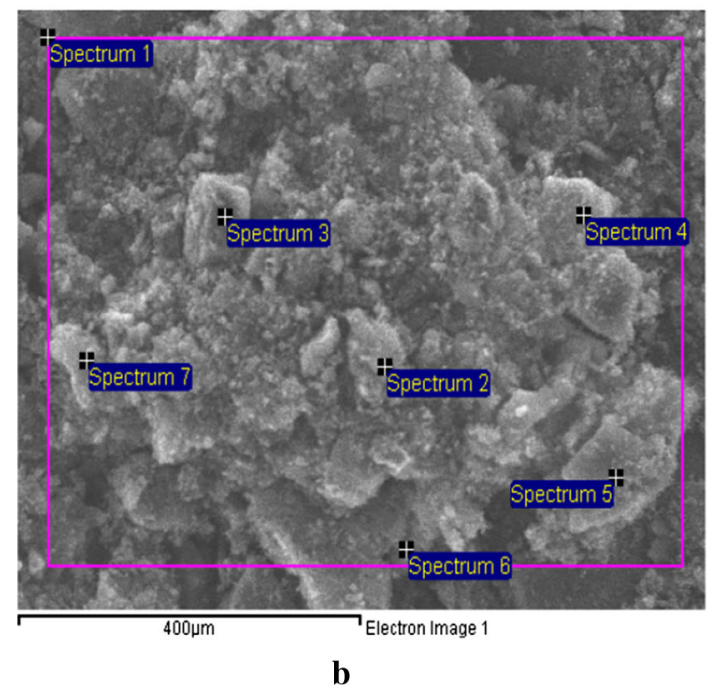

Fig. 3 a TEM image of few-layer graphene, $\mathbf{b}$ the different regions of SEM image of graphene for determination of the elemental analysis. Copied with permission from Moghaddam et al. (2013). Copyright 2014 Elsevier B. V.

\section{Results and discussion}

In this research, adsorption of chromium (VI) ions on graphene was studied through batch system. The adsorption capacity and rate of chromium (VI) ions onto graphene at different temperatures, adsorbent dosages, initial concentrations, and contact times were evaluated. The influence of $\mathrm{pH}$ on the adsorption of $\mathrm{Cr}$ (VI) ions was not investigated by two reasons. The first reason is that $1,5-$ diphenylcarbazide forms a purple-red complex with chromium (VI) ions only in acidic medium (Jankiewicz and Ptaszynski 2005). The recommended $\mathrm{pH}$ is between 1 and 2 since it ensures high sensitivity of the reaction (Jankiewicz and Ptaszynski 2005; Zhu et al. 2011). The second reason can be explained by surface chemistry. The surface of graphene is generally covered with functional groups

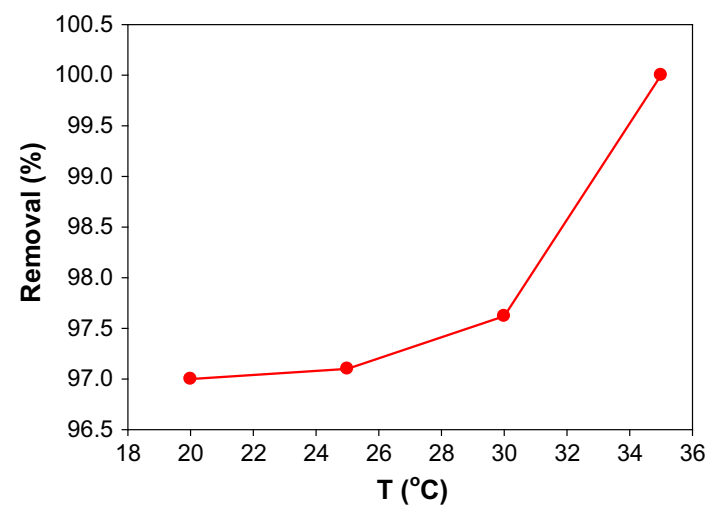

Fig. 4 Influence of temperature on removal efficiency of Cr (VI) ions (graphene dosage: $30 \mathrm{mg}$, initial chromium concentration: $1 \mathrm{ppm}$, and contact time: $60 \mathrm{~min}$ )

containing oxygen-like epoxy and hydroxyl groups. With increasing $\mathrm{pH}$, the concentration of $\mathrm{OH}^{-}$ions increases which competes with $\mathrm{Cr}$ (VI) ions (Zhu et al. 2011). Hence, the uptake of $\mathrm{Cr}(\mathrm{VI})$ ions decreases.

\section{Influence of temperature}

Adsorption experiments were run at 20, 25, 30, and $35{ }^{\circ} \mathrm{C}$ to investigate the influence of temperature with keeping other conditions constant. Figure 4 shows that by raising temperature, the removal efficiency increases. This can be explained by the fact that at lower temperature, the kinetic energy of $\mathrm{Cr}_{2} \mathrm{O}_{7}{ }^{2-}$ anions is low; therefore, contact between $\mathrm{Cr}_{2} \mathrm{O}_{7}{ }^{2-}$ and the active sites of graphene is insufficient leading to a decrease in removal efficiency. Furthermore, at higher temperature, the kinetic energy of the $\mathrm{Cr}_{2} \mathrm{O}_{7}{ }^{2-}$ anion is higher than the attraction potential energy between $\mathrm{Cr}_{2} \mathrm{O}_{7}{ }^{2-}$ and active sites in graphene. This condition causes an increase in removal efficiency. This shows adsorption is more of a physical than a chemical property (Afkhami and Conway 2002). Figure 4 shows that the maximum removal efficiency was found at $35{ }^{\circ} \mathrm{C}$. However, $25{ }^{\circ} \mathrm{C}$ was chosen as an optimum temperature for the next experiments since the value of removal efficiency is also high at this temperature.

Influence of adsorbent dosage

The influence of adsorbent dosage $(1,5,10,20$, and $30 \mathrm{mg}$ graphene) on the adsorption of $\mathrm{Cr}$ (VI) ions at room temperature is shown in Fig. 5. The surface of graphene is decorated with functional groups containing oxygen such as epoxy and hydroxyl groups as Boehm's titration method showed. The large negative charge density available on graphene causes effective adsorption of chromium (VI) ions from aqueous solutions. Figure 5 shows the chromium (VI) 


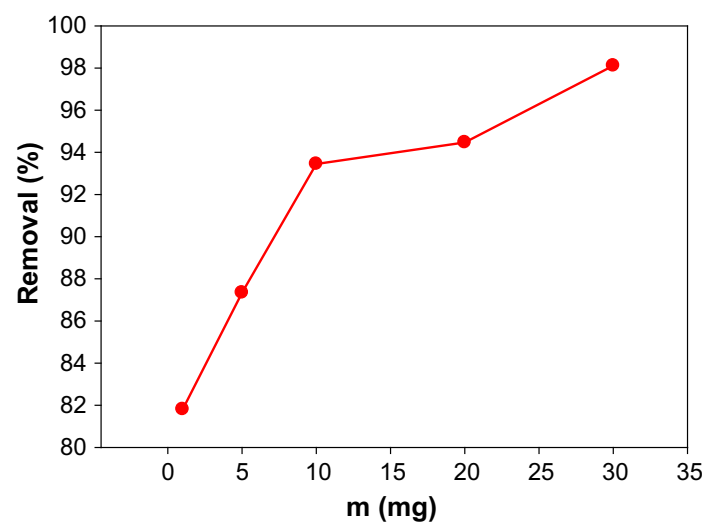

Fig. 5 Influence of graphene dosage on removal efficiencies of $\mathrm{Cr}$ (VI) ions (initial chromium concentration: $1 \mathrm{ppm}$, contact time: $60 \mathrm{~min}$, and temperature: $25^{\circ} \mathrm{C}$ )

ions removal efficiency increases with increasing adsorbent dosage due to the availability of much more adsorption sites. It would be more probable for $\mathrm{HCrO}_{4}{ }^{-}$and $\mathrm{Cr}_{2} \mathrm{O}_{7}{ }^{-}$ions to be adsorbed on adsorption sites. The maximum of removal efficiency achieves for $30 \mathrm{mg}$ of graphene. For this reason, $30 \mathrm{mg}$ graphene was chosen as the optimum value for next experiments.

\section{Influence of initial chromium concentration}

As Fig. 6 shows, the removal efficiency decreases as the initial concentration of $\mathrm{Cr}(\mathrm{VI})$ ions increases. At low initial chromium concentration, the ratio of the available surface area of adsorbent to the initial number of moles of chromium ions is large. Hence, the fractional adsorption becomes independent of initial concentration. However, at higher concentration, the available sites of adsorption become fewer. Hence, the percentage removal of chromium ions which depends upon the initial concentration decreases (Yu et al. 2003).

\section{Influence of contact time}

The adsorption of chromium ions on graphene was investigated as a function of contact time (1-120 min) at three temperatures $\left(20,30\right.$, and $\left.35^{\circ} \mathrm{C}\right)$ (Fig. 7). As Fig. 7 shows, the removal efficiency of chromium (VI) ions from aqueous solution increases rapidly up to $40 \mathrm{~min}$. The high adsorption rate at initial stages may be due to the availability of large number of adsorption sites which saturates with time. The maximum removal efficiency of chromium ions was achieved within $60 \mathrm{~min}$ for all temperatures. There was no significant change in equilibrium concentration after 60 up to $120 \mathrm{~min}$. Therefore, the optimum contact time for adsorption of the chromium ions was considered to be $60 \mathrm{~min}$ at all temperatures.

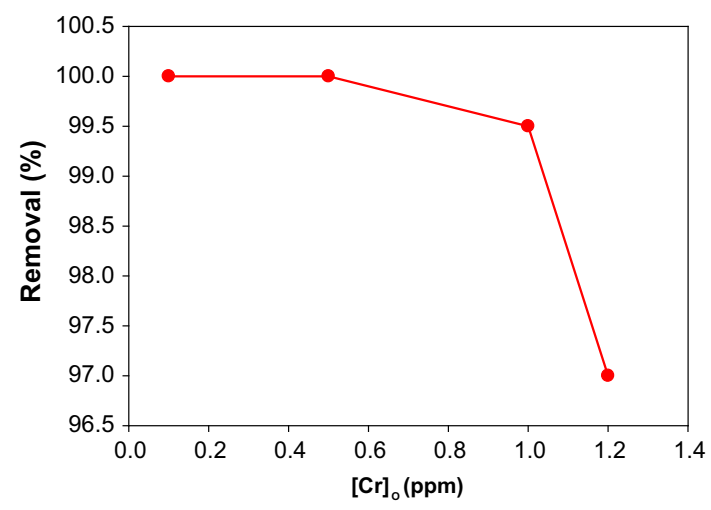

Fig. 6 Influence of chromium concentration on $\mathrm{Cr}$ (VI) ions removal (contact time: $60 \mathrm{~min}$, graphene dosage: $30 \mathrm{mg}$, and temperature: $\left.25{ }^{\circ} \mathrm{C}\right)$



Fig. 7 Percentage removal of $\mathrm{Cr}$ (VI) ions at different times and temperatures (graphene dosage: $30 \mathrm{mg}$ and initial chromium concentration: $1 \mathrm{ppm})$

\section{Adsorption kinetics}

The kinetics of the adsorption describing the Cr (VI) ions uptake rate is one of the important characteristics which controls the residence time of adsorbate uptake at the solid-liquid interface (Zhu et al. 2011). Herein, four kinetic models, namely pseudo-first-order (Largergren 1898), pseudo-second-order (Ho et al. 2000; Mittal et al. 2009), Elovich (Juang and Ju 1998), and intraparticle diffusion (Srivastava et al. 1989), were analyzed. The kinetic equations and the fitting parameters obtained for different models are given in Table 1 . The values of the correlation coefficients obtained from the linear plots of pseudo-firstorder, Elovic, and intraparticle diffusion models are very small $\left(R^{2}<0.97\right)$ suggesting that the applicability of these models to the adsorption processes of $\mathrm{Cr}(\mathrm{VI})$ ions adsorption by graphene is unfeasible. The higher correlation coefficient $\left(R^{2}>0.9995\right)$ is obtained for pseudo-second-order model, indicating that the experimental data are well described by this model. The experimental equilibrium adsorption capacity, $q_{\mathrm{e}}$ was $1.66 \mathrm{mg} \mathrm{g}^{-1}$ at $25^{\circ} \mathrm{C}$ 
Table 1 Used kinetic models

\begin{tabular}{|c|c|c|c|c|c|}
\hline \multirow[t]{2}{*}{ Model } & \multirow[t]{2}{*}{ Equation } & \multirow[t]{2}{*}{$T\left({ }^{\circ} \mathrm{C}\right)$} & \multicolumn{2}{|l|}{ Parameters $^{\mathrm{a}}$} & \multirow[t]{2}{*}{$R^{2}$} \\
\hline & & & $k_{1}\left(\min ^{-1}\right)$ & $q_{\mathrm{e}}\left(\mathrm{mg} \mathrm{g}^{-1}\right)$ & \\
\hline \multirow[t]{5}{*}{ Pseudo-first-order } & \multirow[t]{5}{*}{$\ln \left(q_{\mathrm{e}}-q_{\mathrm{t}}\right)=\ln q_{\mathrm{t}}-k_{1} t$} & 20 & 0.0265 & 0.3472 & 0.4758 \\
\hline & & 25 & 0.0328 & 0.4025 & 0.9555 \\
\hline & & 30 & 0.0415 & 0.7119 & 0.7457 \\
\hline & & 35 & 0.0275 & 0.3522 & 0.9654 \\
\hline & & & $k_{\text {ad }}\left(\mathrm{g} \mathrm{mg}^{-1} \min ^{-1}\right)$ & $q_{\mathrm{e}}\left(\mathrm{mg} \mathrm{g}^{-1}\right)$ & \\
\hline \multirow[t]{5}{*}{ Pseudo-second-order } & \multirow{5}{*}{$\frac{t}{q_{\mathrm{t}}}=\frac{1}{k_{\mathrm{ad}} q_{\mathrm{e}}^{2}}+\frac{t}{q_{\mathrm{e}}}$} & 20 & 0.1270 & 1.6886 & 0.9972 \\
\hline & & 25 & 0.2939 & 1.6804 & 0.9995 \\
\hline & & 30 & 0.1248 & 1.7633 & 0.9991 \\
\hline & & 35 & 0.3915 & 1.6986 & 0.9985 \\
\hline & & & $\alpha\left(\mathrm{g} \mathrm{mg}^{-1} \min ^{-1}\right)$ & $\beta\left(\mathrm{mg} \mathrm{g}^{-1}\right)$ & \\
\hline \multirow[t]{5}{*}{ Elovich } & \multirow{5}{*}{$q_{\mathrm{t}}=\frac{1}{\beta} \ln (\alpha \beta)+\frac{1}{\beta} \ln (t)$} & 20 & 5.2287 & 4.7438 & 0.8499 \\
\hline & & 25 & $15,631.7015$ & 10.1112 & 0.9179 \\
\hline & & 30 & 6.7227 & 4.6838 & 0.8759 \\
\hline & & 35 & $11,997.0849$ & 9.5877 & 0.6693 \\
\hline & & & $K_{\text {dif }}\left(\mathrm{g} \mathrm{mg}^{-1} \min ^{-1}\right)$ & $C\left(\mathrm{mg} \mathrm{g}^{-1}\right)$ & \\
\hline \multirow[t]{4}{*}{ Intraparticle diffusion } & \multirow[t]{4}{*}{$q_{\mathrm{t}}=k_{\mathrm{dif}} t^{0.5}+C$} & 20 & 0.0621 & 1.0280 & 0.7398 \\
\hline & & 25 & 0.0448 & 1.2239 & 0.9327 \\
\hline & & 30 & 0.0267 & 1.4100 & 0.5573 \\
\hline & & 35 & 0.0699 & 1.0921 & 0.7626 \\
\hline
\end{tabular}

a The parameters of the adsorption kinetic models were defined in Zhu et al. (2011)

which is consistent with that of calculated from the pseudosecond-order model $\left(1.68 \mathrm{mg} \mathrm{g}^{-1}\right)$.

The activation energy, $E_{\mathrm{a}}$ for the adsorption of $\mathrm{Cr}$ (VI) ions on graphene was determined using the Arrhenius equation (Sekar et al. 2004),

$\log \frac{k_{2}}{k_{1}}=\frac{E_{\mathrm{a}}\left(T_{2}-T_{1}\right)}{2.303 R T_{2} T_{1}}$

The activation energy was calculated as $21.91 \mathrm{~kJ} \mathrm{~mol}^{-1}$. The activation energies of $5-40 \mathrm{~kJ} \mathrm{~mol}^{-1}$ are characteristics for physisorption, while higher activation energies 40-800 $\mathrm{kJ} \mathrm{mol}^{-1}$ suggests chemisorption (Nollet et al. 2003). Hence, Cr (VI) ions are physically adsorbed on the graphene surface.

Adsorption isotherm and thermodynamic properties

Several isotherm models such as Langmuir (Gupta et al. 2011, 2012b), Freundlich (Mittal et al. 2010b), and Dubinin-Radushkevich (D-R) (Mittal et al. 2010b) can describe the distribution of metal ions between the liquid phase and the solid phase. Isotherm equations and parameters, correlation coefficients $\left(R^{2}\right)$, and definition of isotherm parameters at $25^{\circ} \mathrm{C}$ are presented in Table 2. Table 2 shows that the D-R adsorption isotherm is the best model for describing the chromium ions adsorption on graphene. The value of mean sorption energy, $E$, can be calculated using the following equation (Mittal et al. 2010b):

$E=\frac{1}{\sqrt{-2 \beta}}$

where $\beta\left(\mathrm{mol}^{2} \mathrm{~kJ}^{-2}\right)$ is constant related to the adsorption energy. The value of $E$ in D-R isotherm is very useful in predicting the type of adsorption, and if the value is from 1 to $8 \mathrm{~kJ} \mathrm{~mol}^{-1}$, adsorption is physical in nature, and if it is from 8 to $16 \mathrm{~kJ} \mathrm{~mol}^{-1}$, the adsorption is chemical in nature (Dubinin et al. 1947; Saltal1 et al. 2007; Zheng et al. 2009). The value of $E$ was found to be $3.075 \mathrm{~kJ} \mathrm{~mol}^{-1}$ suggesting the physical nature of the adsorption process in the present study.

The thermodynamic parameters for the adsorption of $\mathrm{Cr}$ (VI) ions on graphene were calculated by the following equations (Karthikeyan et al. 2012; Mittal et al. 2010a)

$\Delta G^{\circ}=-R T \ln (K)$

$\Delta G^{\circ}=\frac{\Delta S^{\circ}}{R}-\frac{\Delta H^{\circ}}{R T}$

where $K$ is the distribution coefficient $\left(K=q_{\mathrm{e}} C_{\mathrm{e}}^{-1}\right), T$ is the temperature $(\mathrm{K}), \quad R$ is the gas constant (8.3145 $\mathrm{J} \mathrm{mol}^{-1} \mathrm{~K}^{-1}$ ). A plot of $\ln K$ versus $T^{-1}$ was found to be linear. The values $\Delta H^{\circ}, \Delta S^{\circ}$, and $\Delta G^{\circ}$ were calculated 
Table 2 Used adsorption isotherms

\begin{tabular}{|c|c|c|c|c|}
\hline Adsorption isotherm & Equation & Parameters $^{\mathrm{a}}$ & & $R^{2}$ \\
\hline Langmuir & $\frac{C_{\mathrm{e}}}{q_{\mathrm{e}}}=\frac{C_{\mathrm{e}}}{q_{\max }}+\frac{1}{q_{\max } k_{\mathrm{L}}}$ & $q_{\max }\left(\mathrm{mg} \mathrm{g}^{-1}\right)=-26.6667$ & $k_{\mathrm{L}}\left(\mathrm{mg} \mathrm{L}^{-1}\right)=-1.9737$ & 0.704 \\
\hline Freundlich & $\log q_{\mathrm{e}}=\log k_{\mathrm{F}}+\frac{1}{n} \log C_{\mathrm{e}}$ & $n=0.7178$ & $k_{\mathrm{F}}\left(\mathrm{mg} \mathrm{g}^{-1}\right)=200.5393$ & 0.993 \\
\hline $\mathrm{D}-\mathrm{R}$ & $\ln q_{\mathrm{e}}=\ln q_{\mathrm{m}}-\beta \varepsilon^{2}$ & $\beta\left(\mathrm{mol}^{2} \mathrm{~kJ}^{-2}\right)=-5.2882 \times 10^{-8}$ & $q_{\mathrm{m}}\left(\mathrm{mg} \mathrm{g}^{-1}\right)=69.9653$ & 0.995 \\
\hline
\end{tabular}

${ }^{a}$ The parameters of the adsorption isotherms were defined in Bhatnagar et al. (2010)

at $25{ }^{\circ} \mathrm{C}$ as $686.07 \mathrm{~kJ} \mathrm{~mol}^{-1}, 2.38 \mathrm{~kJ} \mathrm{~mol}^{-1} \mathrm{~K}^{-1}$, and $-22.43 \mathrm{~kJ} \mathrm{~mol}^{-1}$, respectively. A positive value of $\Delta H^{\circ}$ indicates an endothermic nature of $\mathrm{Cr}$ (VI) ions adsorption. The positive value of $\Delta S^{\circ}$ suggests increased randomness at the solid-solution interface during the adsorption $\mathrm{Cr}$ (VI) ions on the graphene. This indicates strong affinity of the adsorbent for $\mathrm{Cr}$ (VI) ions. Based on the value of $\Delta H^{\circ}$, the adsorption of $\mathrm{Cr}(\mathrm{VI})$ ions on to graphene was a physisorption process. The negative value of $\Delta G^{\circ}$ over the entire temperature range indicates that $\mathrm{Cr}(\mathrm{VI})$ ions adsorption onto the graphene was thermodynamically feasible and can occur spontaneously (Gupta and Nayak 2012; Yao et al. 2012).

\section{Conclusion}

It seems to us this work has the following main conclusions:

Graphene exhibited remarkable removal capacity and fast adsorption rates for chromium (VI) ions removal from aqueous solutions due to the electrostatic attraction between the negative surface oxygen containing groups of graphene and chromium (VI) ions and the $\pi-\pi$ interactions between the chromium (VI) ions and the aromatic rings of graphene.

The removal efficiency of chromium (VI) ions was found to increase with raising temperature, showing the endothermic nature of the adsorption. The maximum of adsorption efficiency (99.5\%) achieves for $30 \mathrm{mg}$ of graphene. The removal percentage increased at the lower initial chromium concentration and higher graphene dosage. The results indicated that the adsorption process reached to equilibrium within $60 \mathrm{~min}$ and after that the adsorption of chromium ions was $100 \%$ at $35^{\circ} \mathrm{C}$.

The adsorption of $\mathrm{Cr}$ (VI) ions obeyed the pseudosecond-order kinetic model. The experimental data for the adsorption process were well fitted by the D-R adsorption isotherm model. The value of $E$ from D-R isotherm suggests the adsorption of $\mathrm{Cr}$ (VI) ions is physical. The thermodynamic parameters indicated that the adsorption of $\mathrm{Cr}$ (VI) ions onto the graphene is spontaneous and endothermic process.
Acknowledgments Financial support from the Ferdowsi University of Mashhad (Grant No. 2/28073) is gratefully acknowledged.

\section{References}

Afkhami A, Conway BE (2002) Investigation of removal of $\mathrm{Cr}(\mathrm{VI})$, $\mathrm{Mo}(\mathrm{VI}), \mathrm{W}(\mathrm{VI}), \mathrm{V}(\mathrm{IV})$, and $\mathrm{V}(\mathrm{V})$ oxy-ions from industrial waste-waters by adsorption and electrosorption at high-area carbon cloth. J Colloid Interface Sci 251:248-255

Badmus M, Audu T, Anyata B (2007) Removal of heavy metal from industrial wastewater using hydrogen peroxide. Afr J Biotechnol 6:238-242

Bhatnagar A, Kumar E, Sillanpää M (2010) Nitrate removal from water by nano-alumina: characterization and sorption studies. Chem Eng J 163:317-323

Cancer IAfRo, Humans IWGotEoCRt (2001) IARC monographs on the evaluation of carcinogenic risks to humans, vol 78 . International Agency for Research on Cancer, Lyon

Chakir A, Bessiere J, Kacemi KE, Marouf B (2002) A comparative study of the removal of trivalent chromium from aqueous solutions by bentonite and expanded perlite. J Hazard Mater 95:29-46

Chakrabarti A, Lu J, Skrabutenas JC, Xu T, Xiao Z, Maguire JA, Hosmane NS (2011) Conversion of carbon dioxide to few-layer graphene. J Mater Chem 21:9491-9493

Deng S, Bai R (2004) Removal of trivalent and hexavalent chromium with aminated polyacrylonitrile fibers: performance and mechanisms. Water Res 38:2424-2432

Dias JM, Alvim-Ferraz M, Almeida MF, Rivera-Utrilla J, SánchezPolo M (2007) Waste materials for activated carbon preparation and its use in aqueous-phase treatment: a review. J Environ Manag 85:833-846

Dubinin MM, Zaverina E, Radushkevich L (1947) Sorption and structure of active carbons. I. Adsorption of organic vapors. Zh Fiz Khim 21:1351-1362

Emsley J (2011) Nature's building blocks: an AZ guide to the elements. Oxford University Press, Oxford

Fu F, Wang Q (2011) Removal of heavy metal ions from wastewaters: a review. J Environ Manag 92:407-418

Gao H, Liu Y, Zeng G, Xu W, Li T, Xia W (2008) Characterization of $\mathrm{Cr}(\mathrm{VI})$ removal from aqueous solutions by a surplus agricultural waste-rice straw. J Hazard Mater 150:446-452

Gardea-Torresdey J et al (2000) Characterization of $\mathrm{Cr}(\mathrm{VI})$ binding and reduction to $\mathrm{Cr}(\mathrm{III})$ by the agricultural byproducts of Avena monida (Oat) biomass. J Hazard Mater 80:175-188

Ghosh PK (2009) Hexavalent chromium [Cr(VI)] removal by acid modified waste activated carbons. J Hazard Mater 171:116-122

Goertzen SL, Thériault KD, Oickle AM, Tarasuk AC, Andreas HA (2010) Standardization of the Boehm titration. Part I. $\mathrm{CO}_{2}$ expulsion and endpoint determination. Carbon 48:1252-1261

Guo P, Song H, Chen X (2009) Electrochemical performance of graphene nanosheets as anode material for lithium-ion batteries. Electrochem Commun 11:1320-1324 
Guo Y, Guo S, Ren J, Zhai Y, Dong S, Wang E (2010) Cyclodextrin functionalized graphene nanosheets with high supramolecular recognition capability: synthesis and host-guest inclusion for enhanced electrochemical performance. ACS Nano 4:4001-4010

Gupta S, Babu B (2006) Adsorption of chromium(VI) by a low-cost adsorbent prepared from tamarind seeds. In: Proceedings of international symposium and 59th annual session of IIChE in association with international partners (CHEMCON-2006), GNFC Complex, Bharuch. Citeseer

Gupta V, Nayak A (2012) Cadmium removal and recovery from aqueous solutions by novel adsorbents prepared from orange peel and $\mathrm{Fe}_{2} \mathrm{O}_{3}$ nanoparticles. Chem Eng J 180:81-90

Gupta VK, Jain R, Nayak A, Agarwal S, Shrivastava M (2011) Removal of the hazardous dye-tartrazine by photodegradation on titanium dioxide surface. Mater Sci Eng, C 31:1062-1067

Gupta VK, Ali I, Saleh TA, Nayak A, Agarwal S (2012a) Chemical treatment technologies for waste-water recycling-an overview. RSC Adv 2:6380-6388

Gupta VK, Jain R, Mittal A, Saleh TA, Nayak A, Agarwal S, Sikarwar S (2012b) Photo-catalytic degradation of toxic dye amaranth on $\mathrm{TiO}_{2} / \mathrm{UV}$ in aqueous suspensions. Mater Sci Eng, C 32:12-17

Ho Y, McKay G, Wase D, Forster C (2000) Study of the sorption of divalent metal ions on to peat. Adsorpt Sci Technol 18:639-650

Hota G, Kumar BR, Ng W, Ramakrishna S (2008) Fabrication and characterization of a boehmite nanoparticle impregnated electrospun fiber membrane for removal of metal ions. J Mater Sci 43:212-217

Jankiewicz B, Ptaszynski B (2005) Determination of chromium in soil of£ ódŸ gardens. Pol J Environ Stud 14:869-875

Juang R-S, Ju C-Y (1998) Kinetics of sorption of Cu(II)-ethylenediaminetetraacetic acid chelated anions on cross-linked, polyaminated chitosan beads. Ind Eng Chem Res 37:3463-3469

Karthikeyan T, Rajgopal S, Miranda LR (2005) Chromium(VI) adsorption from aqueous solution by Hevea brasiliensis sawdust activated carbon. J Hazard Mater 124:192-199

Karthikeyan S, Gupta V, Boopathy R, Titus A, Sekaran G (2012) A new approach for the degradation of high concentration of aromatic amine by heterocatalytic Fenton oxidation: kinetic and spectroscopic studies. J Mol Liq 173:153-163

Kotaś J, Stasicka Z (2000) Chromium occurrence in the environment and methods of its speciation. Environ Pollut 107:263-283

Largergren S (1898) Zur theorie der sogenannten adsorption geloster stoffe. Kungliga Svenska Vetenskapsakademiens. Handlingar 24:1-39

Li Y, Gao B, Wu T, Sun D, Li X, Wang B, Lu F (2009) Hexavalent chromium removal from aqueous solution by adsorption on aluminum magnesium mixed hydroxide. Water Res 43:3067-3075

Lian P, Zhu X, Liang S, Li Z, Yang W, Wang H (2010) Large reversible capacity of high quality graphene sheets as an anode material for lithium-ion batteries. Electrochim Acta 55:3909-3914

Mittal A, Mittal J, Malviya A, Gupta V (2009) Adsorptive removal of hazardous anionic dye "Congo red" from wastewater using waste materials and recovery by desorption. J Colloid Interface Sci 340:16-26

Mittal A, Mittal J, Malviya A, Gupta V (2010a) Removal and recovery of Chrysoidine $\mathrm{Y}$ from aqueous solutions by waste materials. J Colloid Interface Sci 344:497-507

Mittal A, Mittal J, Malviya A, Kaur D, Gupta V (2010b) Decoloration treatment of a hazardous triarylmethane dye, Light Green SF (Yellowish) by waste material adsorbents. J Colloid Interface Sci 342:518-527

Moghaddam MB, Goharshadi EK, Entezari MH, Nancarrow P (2013) Preparation, characterization, and rheological properties of graphene-glycerol nanofluids. Chem Eng J 231:365-372
Nakano Y, Takeshita K, Tsutsumi T (2001) Adsorption mechanism of hexavalent chromium by redox within condensed-tannin gel. Water Res 35:496-500

Nameni M, Moghadam MA, Arami M (2008) Adsorption of hexavalent chromium from aqueous solutions by wheat bran. Int J Environ Sci Technol 5:161-168

Nollet H, Roels M, Lutgen P, Van der Meeren P, Verstraete W (2003) Removal of PCBs from wastewater using fly ash. Chemosphere 53:655-665

Özdemir E, Duranoğlu D, Beker Ü, Avcı AÖ (2011) Process optimization for $\mathrm{Cr}(\mathrm{VI})$ adsorption onto activated carbons by experimental design. Chem Eng J 172:207-218

Park S-J, Jang Y-S (2002) Pore structure and surface properties of chemically modified activated carbons for adsorption mechanism and rate of $\mathrm{Cr}(\mathrm{VI})$. J Colloid Interface Sci 249:458-463

Patterson JW (1985) Industrial wastewater treatment technology. Butterworth-Heinemann, Oxford

Pérez-Candela M, Martín-Martínez J, Torregrosa-Maciá R (1995) Chromium(VI) removal with activated carbons. Water Res 29:2174-2180

Ponder SM, Darab JG, Mallouk TE (2000) Remediation of Cr(VI) and $\mathrm{Pb}$ (II) aqueous solutions using supported, nanoscale zero-valent iron. Environ Sci Technol 34:2564-2569

Saleh TA, Gupta VK (2012) Column with CNT/magnesium oxide composite for lead(II) removal from water. Environ Sci Pollut Res 19:1224-1228

Saltalı K, Sarı A, Aydın M (2007) Removal of ammonium ion from aqueous solution by natural Turkish (Y1ldizeli) zeolite for environmental quality. J Hazard Mater 141:258-263

Sekar M, Sakthi V, Rengaraj S (2004) Kinetics and equilibrium adsorption study of lead(II) onto activated carbon prepared from coconut shell. J Colloid Interface Sci 279:307-313

Srivastava S, Tyagi R, Pant N (1989) Adsorption of heavy metal ions on carbonaceous material developed from the waste slurry generated in local fertilizer plants. Water Res 23:1161-1165

Stafiej A, Pyrzynska K (2007) Adsorption of heavy metal ions with carbon nanotubes. Sep Purif Technol 58:49-52

Su C-Y, Lu A-Y, Xu Y, Chen F-R, Khlobystov AN, Li L-J (2011) High-quality thin graphene films from fast electrochemical exfoliation. ACS Nano 5:2332-2339

Upadhyay RK, Soin N, Roy SS (2014) Role of graphene/metal oxide composites as photocatalysts, adsorbents and disinfectants in water treatment: a review. RSC Adv 4:3823-3851

Wang J, Chen C (2009) Biosorbents for heavy metals removal and their future. Biotechnol Adv 27:195-226

Wang G, Yang J, Park J, Gou X, Wang B, Liu H, Yao J (2008) Facile synthesis and characterization of graphene nanosheets. J Phys Chem C 112:8192-8195

Yao Y, Miao S, Yu S, Ping Ma L, Sun H, Wang S (2012) Fabrication of $\mathrm{Fe}_{3} \mathrm{O}_{4} / \mathrm{SiO}_{2}$ core/shell nanoparticles attached to graphene oxide and its use as an adsorbent. J Colloid Interface Sci 379:20-26

Yu LJ, Shukla SS, Dorris KL, Shukla A, Margrave J (2003) Adsorption of chromium from aqueous solutions by maple sawdust. J Hazard Mater 100:53-63

Zheng H, Liu D, Zheng Y, Liang S, Liu Z (2009) Sorption isotherm and kinetic modeling of aniline on Cr-bentonite. J Hazard Mater 167:141-147

Zhu J et al (2011) One-pot synthesis of magnetic graphene nanocomposites decorated with core@ double-shell nanoparticles for fast chromium removal. Environ Sci Technol 46:977-985 